\title{
Die neun häufigsten Irrtümer über Lyme-Borreliose
}

\author{
Falsche Vorstellungen über Verlauf und \\ Nachweisbarkeit der Lyme-Borreliose \\ sorgen für Fehldiagnosen und Über- \\ therapie. Experten des US-Institute of \\ Medicine (IOM) haben zusammengefasst, \\ was wissenschaftlich wirklich belegt ist.
}

Irrtum Nr. 1: „Bluttests sind unzuverlässig, viele Patienten sind trotz einer Borreliose seronegativ." Weil sich die Immunantwort gegen die Borrelien langsam aufbaut, fallen IgG-Antikörper-Tests in den ersten vier bis sechs Wochen tatsächlich oft negativ aus. In späteren Stadien besteht jedoch, wenn überhaupt, nur äußerst selten Seronegativität. Daher ist bei seronegativen Patienten mit Symptomen, die seit mehr als einem Monat bestehen, eine Borreliosetherapie normalerweise nicht zu rechtfertigen.

Irrtum Nr. 2: „Bei manchen Patienten mit monatelanger Erkrankung sind nur IgM-Antikörper gegen Borrelien nachweisbar." Patienten mit einer Krankheitsdauer von mehr als vier bis sechs Wochen sollten IgG-positiv sein. Der Befund von isoliertem IgM in solchen Patienten ist fast immer falsch positiv. Tests auf spezifisches IgM sollten überhaupt nur in der Frühphase der Erkrankung verwendet werden.

Irrtum Nr. 3: „Positive Antikörper-Tests nach antibiotischer Therapie zeigen an, dass nicht ausreichend behandelt wurde." Eine Persistenz der humoralen Immunantwort nach Abklingen einer Infektion ist normal und kein Zeichen für ein Fortbestehen der Infektion. Bei Patienten mit starker IgG- oder IgM-Reaktion können das Serum und sogar der Liquor selbst nach Jahrzehnten noch seropositiv sein.

Irrtum Nr. 4: „Nach einer Antibiotikatherapie (wegen einer anderen Infektion) können Bluttests negativ ausfallen." Es gibt keinerlei Hinweise, dass eine bestehende Antikörperantwort durch eine nicht kurative Antibiotikagabe supprimiert wird. Selbst nach einer wirksamen Frühtherapie auf Basis eines Wandererythems kommt es bei den meisten Patienten noch zur Serokonversion.

Irrtum Nr. 5: „Die Lyme-Borreliose ist eine klinische Diagnose, die auf der Basis verschie-

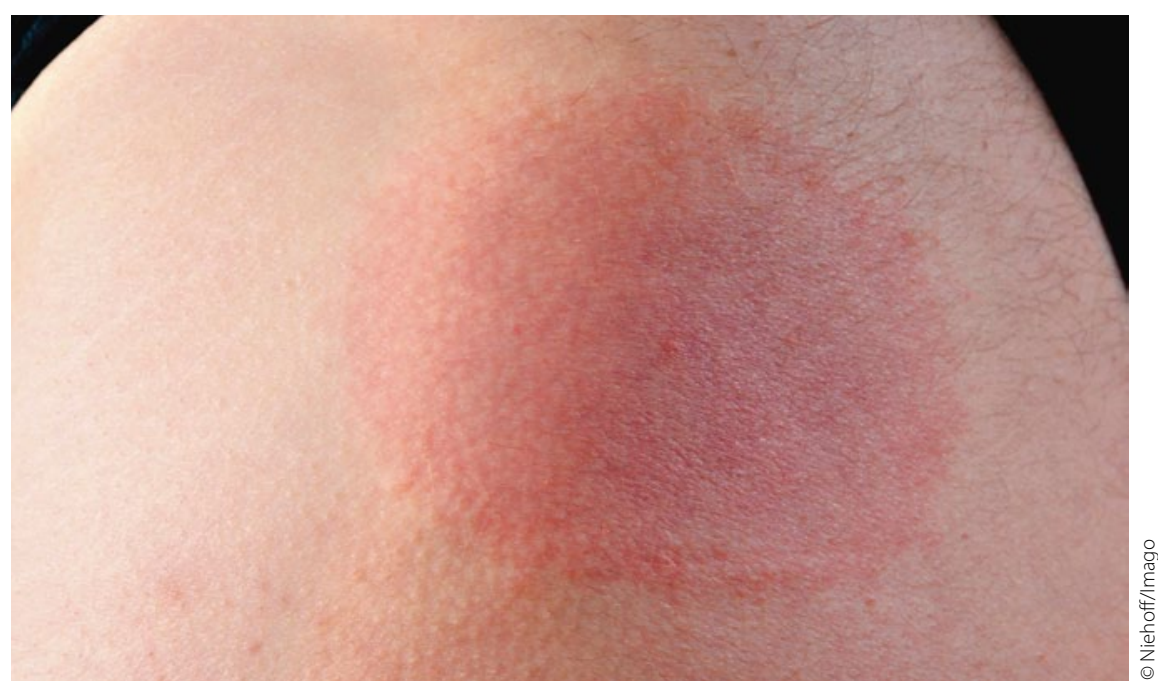

Erythema migrans: klinisches Leitsymptom der Lyme-Borreliose.

dener Symptome zu stellen ist." Es gibt nur ein einziges Symptom, das in Endemiegebieten eine so hohe Spezifität aufweist, dass keine Labordiagnostik nötig ist: das Erythema migrans. Eine beidseitige Lähmung des Gesichtsnervs ist zwar zu 96\% mit einer Borreliose assoziiert, trotzdem ist eine serologische Bestätigung anzuraten. Bei anderen Symptomen wie radikulären Schmerzen ohne mechanische Ursache oder wiederkehrender Oligoarthritis der großen Gelenke ist das Labor unverzichtbar. Eine Diagnosestellung aufgrund noch unspezifischerer Symptome wie Kopfschmerzen, Fatigue und kognitiven Schwierigkeiten ist laut IOM-Publikation „untragbar".

Irrtum Nr. 6: „Patienten mit Fatigue und Gedächtnisproblemen haben eine Borrelieninfektion des zentralen Nervensystems." Bei ca. $10 \%$ der Patienten mit B.-burgdorferi-Infektion kommt es zu einer ZNS-Beteiligung, meist einer Meningitis. Unabhängig davon entwickeln manche Patienten mit aktiver Borreliose Fatigue und/oder Probleme mit Gedächtnis und Kognition. Dahinter steckt keine ZNS-Infektion, vielmehr handelt es sich um eine metabolische Enzephalopathie. Sie ist auch bei anderen Infektionen zu beobachten und wahrscheinlich auf neuroaktive Effekte von löslichen Immunmodulatoren zurückzuführen.
Irrtum Nr. 7: „Eine Borreliose kann tödlich sein." Eine Borreliose kann zwar das Herz oder das Gehirn schädigen, ein tödlicher Verlauf ist nach den vorliegenden Daten trotzdem extrem unwahrscheinlich.

Irrtum Nr. 8: „Wenn die Symptome nach Antibiotikatherapie fortbestehen, muss länger behandelt werden." In aller Regel genügt eine Antibiotikatherapie von zwei bis vier Wochen. In kontrollierten Studien hat eine längere Therapie auch bei anhaltenden Symptomen keinen Zusatznutzen erbracht. Irrtum Nr. 9: "Wenn es unter der Therapie zu einer schnellen Besserung der Symptome kommt, beweist dies die Richtigkeit der Diagnose auch bei negativer Serologie." Eine Besserung der Symptome kann auch auf das Abklingen einer anderen Infektion, auf einen Placeboeffekt oder auf andere nicht antimikrobielle Wirkungen der Antibiotika zurückgehen. Genauso wenig wie nach der Therapie persistierende Symptome gegen die Diagnose sprechen, kann die Besserung unspezifischer oder neurologischer Symptome als Beweis dafür angeführt werden.

\section{DR. BEATE SCHUMACHER .}

- Halperin JJ et al. Common Misconceptions About Lyme Disease. American Journal of Medicine 2013; online 14. Januar 2013 